\title{
Assessment of postural balance in multiple sclerosis patients
}

\author{
Abdulalim Atteya ${ }^{1}$, Abeer Elwishy $^{1}$, Nirmeen Kishk ${ }^{2}$, Rania Shehata Ismail ${ }^{2 *}$ and Rania Badawy ${ }^{1}$
}

\begin{abstract}
Background: Disturbance of balance and falls are commonly observed in people with multiple sclerosis (MS).

Objectives: The aim of this study is to assess the postural balance in patients with MS by using clinical and instrumental methods and to specify the most direction of balance instability among MS patients using Biodex stability system (BSS).

Methods: Fifty ambulatory individuals with MS [42 relapsing-remitting (RRMS) and 8 secondary progressive (SPMS)] were evaluated for balance using quantitative Berg balance scale (BBS) and BSS. Twenty healthy volunteers were selected as a control group.

Results: There was a statistically significant difference between the patient and control groups assessed by BBS. Moreover, patients with SPMS had worse postural balance when compared with RRMS. According to BSS, MS group showed more sway in the three limits of stability (mediolateral, antroposterior, and overall) when compared to the control group. The least stability level was observed in mediolateral direction in the patient group. The degree of tilt was higher in SPMS than RRMS as regard the three limits of stability. The BBS was significantly negatively correlated with age, Expanded Disability Status Scale (EDSS), duration of illness, and the Biodex tilt. Also, there were positive significant correlation between age, EDSS score, and the duration of illness of the disease with parameters of BSS (mediolateral, antroposterior, and overall).
\end{abstract}

Conclusion: BSS was significantly correlated with clinical balance measurement scale using BBS in MS patients. Moreover, BSS can provide more objective, quantitative measures of postural imbalance.

Keywords: MS, Balance, Berg balance scale, Biodex stability system

\section{Introduction}

Multiple sclerosis is one of the most frequent neurological diseases in young adults and its prevalence shows a heterogeneous distribution among countries [1, 2]. Lack of balance and falls are among the most disabling symptoms of multiple sclerosis and may affect about $75 \%$ of patients over the course of the disease [3]. Balance impairment reduces mobility and independence, leads to falls and injuries, impacts upon overall quality of life [4]. Imbalance in multiple sclerosis (MS) remains incurable with major burden on the society [5].

Deficiency in any one of the multiple sensory or motor mechanisms of the postural system can produce dramatic effects on postural stability and motor

\footnotetext{
* Correspondence: raniashehata.neuro@yahoo.com

${ }^{2}$ Neurology Department, Faculty of Medicine, Cairo University, Cairo, Egypt Full list of author information is available at the end of the article
}

performance. Numerous factors including biometric factors, physiological functions, cognitive processing, visual feedback, and cerebellar activity have shown to influence postural sway [6].

Clinical tests usually rate balance performance on a set of motor tasks. Scoring is based on the sum of ordinal item scores. Ideally, an evaluation of postural balance should include clinical scales that are practical, sensitive, selective, reliable, and valid. Although some clinical scales are easy and relatively quick to use, they are hampered by their variable execution $[7,8]$.

The Biodex stability system (BSS) was used to assess the participant's dynamic balance. It is used for both assessment and training of the dynamic balance, and dynamic limits of stability. It focuses on the proprioceptive neuromuscular mechanisms that appear to affect both dynamic joint and postural stabilities $[9,10]$. 
The aim of this study were to assess the postural balance in patients with MS by using clinical and instrumental methods and to determine the differences in the directions of tilt of the instrumental method (Biodex stability system) which may help in the rehabilitation programs of the patients.

\section{Subjects and methods}

This case-control study was conducted on 50 patients with multiple sclerosis either relapsing-remitting multiple sclerosis (RRMS) or secondary progressive multiple sclerosis (SPMS) (mean age $=30.06 \pm 7.7$ years, $\mathrm{M}: \mathrm{F}=$ 16:34) diagnosed according to McDonald's criteria 2017 [11], recruited from outpatient clinic of Faculty of Medicine, Cairo University. Expanded Disability Status Scale (EDSS) of these patients is $<5$. Patients with RRMS were being in remission period (at least 2 months after last relapse). Twenty healthy volunteers were selected as a control group matching in age, gender, weight, and height to patients. Informed written consent was obtained from participants and the study was approved by the ethical committee of Department of Physical Therapy for Neuromuscular Disorders and its Surgery, Faculty of Physical Therapy, Cairo University. Registration number (NO:P.T.REC/010/001075).

Excluded from this study are patients with cognitive impairments (MMSE $\leq 24)$ [12], patients with skeletal deformities in lower limbs, diabetes mellitus, as well as patients with visual and internal ear dysfunction.

Patients were subjected to (a) complete general and neurological examination including EDSS [13]. (b) Clinical assessment of balance using Berg balance scale (BBS) which consists of 14 standardized sub-tests scored on 5 -point scales (0-4), with a maximum score of 56 (the best performance) examining individuals' ability to sit, stand, reach, maintain single-leg stance, and turn [14]. Scores less than 45 were considered as faller [15]. (c) Instrumental assessment of balance using BSS. The system supplies with data regarding the balance of the tested subject. This data include anteroposterior (AP) stability index, mediolateral (ML) stability index, and overall stability index. The smaller the amount of the sway, the lower the numerical value of these indices will be [16].

\section{Statistical methods}

Data was analyzed using SPSS version 21. Numerical data will be expressed as mean and standard deviation. Frequency and percentage for qualitative data, student $t$ test will be used to compare the difference between two means of quantitative variables among patients and controls, chi-square test will be used to compare qualitative variables, and correlation was done using Spearman rank coefficient to study the relation between numeric variables. Paired $t$ test was used to compare two means in the same patients; level of significant was at $p$ value $\leq 0.05$.

\section{Results \\ General characteristics of the subjects Patient group}

Fifty patients with multiple sclerosis (16 males and 34 females) were included in this group. Their mean age was $30.06 \pm 7.7$ years, mean weight was $70.28 \pm 11.36 \mathrm{~kg}$, mean height was $161.46 \pm 7.5 \mathrm{~cm}$, and mean body mass index (BMI) was $26.97 \pm 4.16 \mathrm{~kg} / \mathrm{m}^{2}$.

\section{Control group}

Twenty healthy volunteer subjects (7 males and 13 females) were included. Their mean age was $29.9 \pm 4.81$ years, mean weight was $78.9 \pm 21.01 \mathrm{~kg}$, mean height was $164.9 \pm$ $8.91 \mathrm{~cm}$, and mean BMI was $28.80 \pm 6.81 \mathrm{~kg} / \mathrm{m}^{2}$.

There was no statistically significant difference between both groups regarding age, gender, weight, height, and BMI ( $p$ value $>0.05)$.

\section{Clinical characteristics of patients}

Patient group consisted of 50 patients, 42 (84\%) had RRMS and 8 (16\%) patients had SPMS. The mean values of the age, weight, height, BMI, duration of illness, and EDSS were represented in (Table 1).

\section{Clinical assessment of the balance using Berg balance scale} test

In patient group, there were 39 (78\%) subjects concerned as non-fallers (score between 56 and 45 in BBS according to Riddle and Stratford [18], while 11 (22.0\%) subjects were concerned as fallers (score less than 45). In the control group, all subjects were detected as non-faller (100\%). There was significant difference between both groups ( $p$ value $=0.027)$. Also, there was a significant difference between RRMS and SPMS regarding BBS score $(p$ value $=0.001)$.

Table 1 Demographic and clinical data of patient subgroups

\begin{tabular}{|c|c|c|c|c|c|}
\hline & \multicolumn{2}{|c|}{$\operatorname{RRMS}(n=42)$} & \multicolumn{2}{|c|}{$\operatorname{SPMS}(n=8)$} & \multirow[t]{2}{*}{$P$ value } \\
\hline & Mean & $\mathrm{SD} \pm$ & Mean & $\mathrm{SD} \pm$ & \\
\hline Age (years) & 29.74 & 7.99 & 31.75 & 6.07 & 0.504 \\
\hline Weight (kg) & 70.74 & 11.97 & 67.88 & 7.55 & 0.519 \\
\hline Height (cm) & 160.48 & 7.16 & 166.63 & 7.56 & $0.032^{a}$ \\
\hline BMI $\left(\mathrm{kg} / \mathrm{m}^{2}\right)$ & 27.46 & 4.34 & 24.38 & 1.30 & $0.001^{a}$ \\
\hline Duration of illness & 4.36 & 3.52 & 6.38 & 1.51 & $0.040^{a}$ \\
\hline EDSS & 2.69 & 1.11 & 3,94 & 1.05 & $0.009^{a}$ \\
\hline
\end{tabular}

${ }^{\mathrm{a}}$ Statistically significant $<0.05$ 
Comparison between patient and control groups as regard the stability indices of BSS

There were significant differences between patient and control group as regard the three limits of stability mediolateral, anteroposterior, and overall ( $p$ value $=0.001$, 0.005 , and 0.002 ) respectively as shown in (Table 2 ).

\section{Comparison between the deviation (tilt) in anteroposterior and mediolateral direction in patient group}

By using Biodex stability system (BSS), the mediolateral and antroposterior directions cutoff values in the patient group were $1.79^{\circ}$ and $2.26^{\circ}$ respectively (as regard the control cutoff values). The least stability level was observed in mediolateral direction in the patient group ( $p$ value $=0.001)($ Table 3$)$.

\section{Comparison between the patient subgroups (RRMS and SPMS) as regard stability indices of BSS}

The degree of tilt was higher in SPMS than RRMS as regard the three limits of stability mediolateral, anteroposterior, and overall ( $p$ value $=0.009,0.001$, and 0.003) respectively.

\section{The relation between $B B S$ and $B S S$}

In MS patients, the faller group showed more significant deviation than non-faller group in the three directions (anteroposterior, mediolateral, and overall) ( $p$ value $=$ $0.002,0.001$, and 0.001 ) respectively as shown in (Table 4).

\section{Correlation between BBS and the patient data}

The Berg balance scale (BBS) was significantly negatively correlated with age, EDSS, duration of illness, and the Biodex tilt in the three different directions (mediolateral, antroposterior, and overall). Also, there were positive correlation between BBS and weight, height and BMI. This is shown in (Table 5).

\section{Correlation between the BSS and the patients' data}

There were positive significant correlation between age, EDSS score, and the duration of illness of the disease with parameters of BSS (mediolateral, antroposterior, and overall). Also, there was a negative correlation

Table 2 Comparison between patient and control groups as regard the stability indices of BSS

\begin{tabular}{llll}
\hline BSS & $\begin{array}{l}\text { Patient group }(n=50) \\
\text { Mean } \pm \text { SD } \\
\text { Degree/second }\end{array}$ & Control group $(n=20)$ & $\begin{array}{l}P \\
\text { value }\end{array}$ \\
\hline ML & $1.83 \pm .49$ & $1.40 \pm .39$ & $0.001^{\text {a }}$ \\
AP & $2.16 \pm .98$ & $1.58 \pm .68$ & $0.005^{\text {a }}$ \\
OA & $2.75 \pm 1.06$ & $2.00 \pm .75$ & $0.002^{\text {a }}$
\end{tabular}

$B S S$ Biodex stability system, $M L$ mediolateral, $A P$ antroposterior, $O A$ overall ${ }^{\text {a }}$ Statistically significant $<0.05$
Table 3 Comparison between anteroposterior and mediolateral tilt in patient group

\begin{tabular}{llll}
\hline & ML insignificant tilt & ML significant tilt & $P$ value \\
\hline AP insignificant tilt & 20 & 12 & $0.001^{\text {a }}$ \\
AP significant tilt & 1 & 17 &
\end{tabular}

$B S S$ Biodex stability system, $M L$ mediolateral, $A P$ antroposterior, $O A$ overall N.B. The mediolateral and antroposterior directions cutoff values in the patient group were $1.79^{\circ}$ and $2.26^{\circ}$ respectively (as regard the control cutoff values)

${ }^{\text {a }}$ Statistically significant $<0.05$

between weight, height, BMI, and BBS with the parameters of BSS (Table 6).

\section{Discussion}

In patients with MS, balance deficits and the associated fear of falling result in significant declines in their mobility and activity levels, decreased social contact [17]. Balance assessment is necessary for multiple sclerosis subjects in rehabilitation settings. It helps establishing appropriate treatment goals. Also, it is important to increase awareness of fall risk and to assign appropriate assistive devices [18, 19].

BBS is used as screening tool for balance problems in people with MS [20]. Assessment of balance by BBS test revealed significant difference between patient and control groups in the present study. This was in agreement with Finlayson and colleagues. Finlayson et al. [21] and Nilsagard et al. [22] found that the balance impairment can be associated with increased risk of fall in MS patients when measuring by BBS. On the other hand, Fjeldstad and colleagues [20] reported that BBS measures mainly the static balance and does not provide significant information about dynamic functions. In contrast to the present study, Findling and colleagues [23] found that the use of clinical balance protocols (BBS) did not identify any balance abnormalities. This may be attributed to the sample of patients chosen in that study as they were minimally impaired MS patients with EDSS scores less than 3 .

According to the current study, there was a significant difference between RRMS and SPMS groups as regard BBS score. There was more instability found in SPMS group than RRMS group. In agreement with the present

Table 4 Comparison between fallers and non-fallers as regard the degree of tilt in the limits of the stability of BSS

\begin{tabular}{llll}
\hline BSS & $\begin{array}{l}\text { Non faller }(n=39) \\
\text { Mean } \pm \text { SD } \\
\text { Degree/second }\end{array}$ & Faller $(n=11)$ & $\begin{array}{l}P \\
\text { value }\end{array}$ \\
\hline ML & $1.73 \pm .46$ & $2.22 \pm .40$ & $0.002^{\mathrm{a}}$ \\
AP & $1.85 \pm .70$ & $3.26 \pm 1.06$ & $0.001^{\text {a }}$ \\
OA & $2.42 \pm .79$ & $3.94 \pm 1.08$ & $0.001^{\text {a }}$
\end{tabular}

BSS Biodex stability system, $M L$ mediolateral, $A P$ antroposterior, $O A$ overall ${ }^{a}$ Statistically significant $<0.05$ 
Table 5 Correlations between BBS and the patients' data

\begin{tabular}{lll}
\hline & Correlation coefficient $(r)$ of BBS & $P$ value \\
\hline Age & -0.402 & $0.004^{\mathrm{a}}$ \\
Weight & 0.303 & $0.032^{\mathrm{a}}$ \\
Height & 0.014 & 0.922 \\
BMl & 0.332 & $0.019^{\mathrm{a}}$ \\
EDSS & -0.725 & $0.001^{\mathrm{a}}$ \\
Duration of illness & -0.508 & $0.001^{\mathrm{a}}$ \\
& & \\
& & \\
ML & -0.694 & $0.001^{\mathrm{a}}$ \\
AP & -0.784 & $0.001^{\mathrm{a}}$ \\
OA & -0.804 & $0.001^{\mathrm{a}}$ \\
\hline
\end{tabular}

$B M I$ Body mass index, EDSS Expanded Disability Status Scale, BSS Biodex stability system, $M L$ mediolateral, $A P$ antroposterior, $O A$ overall

${ }^{\text {a }}$ Statistically significant $<0.05$

study, Soyuer and colleagues [19] found that patients with MS report worse postural balance and increased risk of falls when compared with healthy controls. This is more significant for those with progressive forms of MS rather than the relapsing remitting form of MS.

Instrumental measures of balance may be more sensitive than common clinical tests for documenting both deficits and improvements in balance, even in minimally impaired patients with MS [24]. According to the current study, assessment with the Biodex stability system (BSS) revealed that the MS group demonstrated greater postural sway in the three limits of stability compared with healthy control group. The least stability level was observed in mediolateral direction. Also, the SPMS group showed more instability than the RRMS group in all tilting directions. Moreover, there were significant differences between fallers and non-fallers as regard BSS

Table 6 Correlation between BSS parameters (mediolateral, anteroposterior, and overall) and the patients' data

\begin{tabular}{|c|c|c|c|c|}
\hline & & $M L$ & AP & $\mathrm{OA}$ \\
\hline Age & $\begin{array}{l}r \\
p \text { value }\end{array}$ & $\begin{array}{l}0.311 \\
0.028^{\mathrm{a}}\end{array}$ & $\begin{array}{l}0.366 \\
0.009^{a}\end{array}$ & $\begin{array}{l}0.343 \\
0.015^{a}\end{array}$ \\
\hline Weight & $\begin{array}{l}r \\
p \text { value }\end{array}$ & $\begin{array}{l}-0.241 \\
0.092\end{array}$ & $\begin{array}{l}-0.073 \\
0.614\end{array}$ & $\begin{array}{l}-0.134 \\
0.352\end{array}$ \\
\hline Height & $\begin{array}{l}r \\
p \text { value }\end{array}$ & $\begin{array}{l}-0.032 \\
0.827\end{array}$ & $\begin{array}{l}-0.053 \\
0.712\end{array}$ & $\begin{array}{l}-0.012 \\
0.937\end{array}$ \\
\hline BMI & $\begin{array}{l}r \\
p \text { value }\end{array}$ & $\begin{array}{l}-0.249 \\
0.081\end{array}$ & $\begin{array}{l}-0.117 \\
0.420\end{array}$ & $\begin{array}{l}-0.157 \\
0.275\end{array}$ \\
\hline EDSS & $\begin{array}{l}r \\
p \text { value }\end{array}$ & $\begin{array}{l}0.601 \\
0.001^{a}\end{array}$ & $\begin{array}{l}0.625 \\
0.001^{a}\end{array}$ & $\begin{array}{l}0.667 \\
0.001^{\mathrm{a}}\end{array}$ \\
\hline Duration of illness & $\begin{array}{l}r \\
p \text { value }\end{array}$ & $\begin{array}{l}0.363 \\
0.010^{a}\end{array}$ & $\begin{array}{l}0.356 \\
0.011^{a}\end{array}$ & $\begin{array}{l}0.381 \\
0.006^{\mathrm{a}}\end{array}$ \\
\hline BBS & $\begin{array}{l}r \\
p \text { value }\end{array}$ & $\begin{array}{l}-0.694 \\
0.001^{\mathrm{a}}\end{array}$ & $\begin{array}{l}-0.784 \\
0.001^{a}\end{array}$ & $\begin{array}{l}-0.804 \\
0.001^{\mathrm{a}}\end{array}$ \\
\hline
\end{tabular}

$M L$ mediolateral, $A P$ antroposterior, $O A$ overall

${ }^{\mathrm{a}}$ Statistically significant $<0.05$ assessment in the three directions of tilt. Fjeldstad and colleagues [20] found that there was a significant difference between the MS and healthy control groups for both static and dynamic balance using BBS and NeuroCom SMART Balance Master. They found a significant correlation between the postural assessments using the standard BBS and approximately $70 \%$ of all tests performed with the NeuroCom balance tests for the MS group. Moreover, Findling and colleagues [23] reported significant balance changes in MS patients compared to healthy subjects on a normal surface in both anteroposterior and mediolateral direction, while standing on two legs with eyes opened. Also, they found significant differences for angular range velocity in the mediolateral direction. Furthermore, Sosnoff and colleagues [24] found that faller subjects exhibited increased sway velocity in the ML direction with eyes opened more than the anteroposterior direction compared to non-faller subjects. This was in agreement with the present results. The current study findings are contrary to Cattaneo and colleagues [25] who found that the patients in MS group showed more instability than the healthy subjects in anteroposterior direction more than mediolateral direction.

According to the present results, the possibility of falling according to the BBS and BSS assessment increases in older patients, patients with higher score of EDSS, and those with increased duration of illness. This was in accordance with Sosnoff and colleagues [24] who observed that people with MS who are older, walk slower, and have worse balance and decreased walking endurance are at a greater risk of falls. Also, Prosperini and colleagues [3] found that fallers had a longer disease duration and worse EDSS and had lower BBS scores than non-fallers. According to Nilsagard and colleagues [22], they found that there were significant differences between fallers and non-fallers with regard to EDSS and for each degree of increased EDSS score, the odds of falling were doubled.

From all previous results, we conclude that BSS was significantly correlated with clinical balance measurement scale using BBS in MS patients. Moreover, BSS can provide more objective, quantitative measures of postural imbalance. This may help in applying the suitable rehabilitation program of the patients.

\section{Abbreviations}

BBS: Berg balance scale; BSS: Biodex stability system; EDSS: Expanded Disability Status Scale; MS: Multiple sclerosis; RRMS: Relapsing-remitting multiple sclerosis; SPMS: Secondary progressive multiple sclerosis

\section{Acknowledgements}

The authors acknowledge subjects for their participation and cooperation in this study.

\section{Funding}

This research received no specific grant from any funding agency in the public, commercial, or not-for-profit sectors. 


\section{Availability of data and materials}

The datasets generated and/or analyzed during the current study are not publicly available due to current Cairo University regulations \& Egyptian legislation but are available from the corresponding author on reasonable request and after institutional approval.

\section{Authors' contributions}

$\mathrm{AA}$, NK, and AE contributed in research idea, data acquisition, data analysis, and interpretation. RS contributed in data analysis, interpretation, and manuscript writing and reviewing. RB contributed in data acquisition, data analysis, and interpretation. All authors read and approved the final manuscript.

\section{Ethics approval and consent to participate}

The aim and procedures of the study were explained to every participant and an informed consent was obtained before being enrolled in the study. The study was approved by the ethical committee of Department of Physical Therapy for Neuromuscular Disorders and its Surgery, Faculty of Physical Therapy, Cairo University. (NO:P.T.REC/010/001075). (12/10/2015).

\section{Consent for publication}

Not applicable.

\section{Competing interests}

The authors declare that we have no competing interests (financial and nonfinancial). We declare that the research was conducted in absence of any commercial relationships that could be constructed as a potential conflict of interest.

\section{Publisher's Note}

Springer Nature remains neutral with regard to jurisdictional claims in published maps and institutional affiliations.

\section{Author details}

'Department of Physical Therapy for Neuromuscular Disorder and its Surgery, Faculty of Physical Therapy, Cairo University, Cairo, Egypt. ${ }^{2}$ Neurology Department, Faculty of Medicine, Cairo University, Cairo, Egypt.

Received: 20 September 2018 Accepted: 17 December 2018 Published online: 18 January 2019

\section{References}

1. Yahia A, Ghroubi S, Mhiri C, Elleuch MH. Relationship between muscular strength, gait and postural parameters in multiple sclerosis. Ann Phys Rehabil Med. 2011;54(3):144-55.

2. Rosati G. The prevalence of multiple sclerosis in the world: an update. Neurol Sci. 2001;22(2):117-39.

3. Prosperini L, Fortuna D, Giannì C, Leonardi L, Pozzilli C. The diagnostic accuracy of static posturography in predicting accidental falls in people with multiple sclerosis. Neurorehabil Neural Repair. 2013;27(1):45-52.

4. Gunn HJ, Newell P, Haas B, Marsden JF, Freeman JA. Identification of risk factors for falls in multiple sclerosis: a systematic review and meta-analysis. Phys Ther. 2013;93(4):504-13.

5. Thompson AJ, Toosy AT, Ciccarelli O. Pharmacological management of symptoms in multiple sclerosis: current approaches and future directions. Lancet Neurol. 2010;9(12):1182-99.

6. Fasano A, Plotnik M, Bove F, Berardelli A. The neurobiology of falls. Neurol Sci. 2012:33(6):1215-23.

7. Visser JE, Carpenter MG, van der Kooij H, Bloem BR. The clinical utility of posturography. Clin Neurophysiol. 2008;119(11):2424-36.

8. Mancini M, Horak FB. The relevance of clinical balance assessment tools to differentiate balance deficits. Eur J Phys Rehabil Med. 2010;46(2):239-48.

9. Cachupe WJ, Shifflett B, Kahanov L, Wughalter EH. Reliability of biodex balance system measures. Meas Phys Educ Exerc Sci. 2001;5(2):97-108.

10. Parraca JA, Olivares PR, Carbonell-Baeza A, Aparicio VA, Adsuar JC, Gusi N. Test-retest reliability of Biodex balance SD on physically active old people. Journal Hum Sport Exerc. 2011:6(2):444-51.

11. Thompson AJ, Banwell BL, Barkhof F, Carroll WM, Coetzee T, Comi G, et al. Diagnosis of multiple sclerosis: 2017 revisions of the McDonald criteria. Lancet Neuro. 2017;17(2):103-92.
12. Tombaugh TN, McIntyre NJ. The mini-mental state examination: a comprehensive review. J Am Geriatr Soc. 1992;40(9):922-35.

13. Kurtzke JF. Rating neurologic impairment in multiple sclerosis: an expanded disability status scale (EDSS). Neurology. 1983;33(11):1444-52.

14. Berg KO, Wood-Dauphinee SL, Williams JI, Maki B. Measuring balance in the elderly: validation of an instrument. Canadian journal of public health $=$ revue canadienne de. Sante Publique. 1992;83:S7-11.

15. Cattaneo D, Regola A, Meotti M. Validity of six balance disorders scales in persons with multiple sclerosis. Disabil Rehabil. 2006;28(12):789-95.

16. Finn JA, Alvarez MM, Jett RE, Axtell RS, Kemler DS. Stability performance assessment among subjects of disparate balancing abilities. Med Sci Sports Exerc. 1999;31(5):S252.

17. Scheffer AC, Schuurmans MJ, Van Dijk N, Van Der Hooft T, De Rooij SE. Fear of falling: measurement strategy, prevalence, risk factors and consequences among older persons. Age Ageing. 2008:37(1):19-24.

18. Vaney C, Vaney S, Wade DT. SaGA S, the short and graphic a bility score: an alternative scoring method for the motor components of the multiple sclerosis functional C omposite. Mult Scler J. 2004;10(2):231-42

19. Soyuer F, Mirza M, Erkorkmaz Ü. Balance performance in three forms of multiple sclerosis. Neurol Res. 2006;28(5):555-62.

20. Fjeldstad C, Pardo G, Frederiksen C, Bemben D, Bemben M. Assessment of postural balance in multiple sclerosis. Int J MS Care. 2009:11(1):1-5.

21. Finlayson ML, Peterson EW, Cho CC. Risk factors for falling among people aged 45 to 90 years with multiple sclerosis. Arch Phys Med Rehabil. 2006; 87(9):1274-9.

22. Nilsagård $Y$, Lundholm C, Denison E, Gunnarsson LG. Predicting accidental falls in people with multiple sclerosis - a longitudinal study. Clin Rehabil. 2009;23(3):259-69.

23. Findling $\mathrm{O}$, Sellner J, Meier N, Allum JH, Vibert D, Lienert C, et al. Trunk sway in mildly disabled multiple sclerosis patients with and without balance impairment. Exp Brain Res. 2011;213(4):363-70.

24. Sosnoff JJ, Socie MJ, Boes MK, Sandroff BM, Pula JH, Suh Y, et al. Mobility, balance and falls in persons with multiple sclerosis. PLoS One. 2011;6(11): e28021

25. Cattaneo D, Ferrarin M, Jonsdottir J, Montesano A, Bove M. The virtual time to contact in the evaluation of balance disorders and prediction of falls in people with multiple sclerosis. Disabil Rehabil. 2012;34(6):470-7.

\section{Submit your manuscript to a SpringerOpen ${ }^{\circ}$ journal and benefit from:}

- Convenient online submission

- Rigorous peer review

- Open access: articles freely available online

- High visibility within the field

- Retaining the copyright to your article

Submit your next manuscript at $>$ springeropen.com 